\title{
Práticas insurgentes e contrapoderes no planejamento urbano: o caso de Pointe- Saint-Charles em Montreal
}

\author{
Insurgent practices and counterpowers in urban planning: the case of Pointe-Saint- \\ Charles in Montreal
}

Anne Latendresse[a], Luis Felipe Cunha ${ }^{[b]}$ (1)

[a] Université du Québec à Montréal (UQAM), Département de Géographie, Montréal, QC, Canada

[b] Universidade Federal de Santa Catarina (UFSC), Programa de Pós-graduação em Geografia, Florianópolis, SC Brasil

Como citar: Latendresse, A., \& Cunha, L. F. (2019). Práticas insurgentes e contrapoderes no planejamento urbano: o caso de Pointe-Saint-Charles em Montreal. urbe. Revista Brasileira de Gestão Urbana, 11, e20180041. https://doi.org/10.1590/2175-3369.011.002.A015

\section{Resumo}

Antigo berço da industrialização canadense, Pointe-Saint-Charles é um bairro localizado próximo ao centro da cidade de Montreal, Quebec, em confronto com um acelerado processo de revitalização urbana a partir dos anos 1990. Diante desse processo recente, organizações populares locais têm empreendido diversificadas lutas, como as Operações Populares de Planejamento (OPAs), cuja primeira experiência ocorreu em 2004. Busca-se conhecer em que medida essas práticas são capazes de influenciar o poder decisório que atua sobre a trama territorial local. Desse modo, o objetivo deste artigo é compreender de que modo as OPAs em Pointe-Saint-Charles se constituem em práticas de um planejamento insurgente, nos termos definidos por Miraftab $(2009 ; 2016)$ e Purcell (2009). A metodologia utilizada envolveu a revisão do conceito de planejamento insurgente, além da coleta de dados primários, como depoimentos, consulta a documentos comunitários e visitas técnicas ao referido bairro montrealês. Conclui-se que as OPAs em Pointe-Saint-Charles se constituem em importantes espaços de contrapoder em relação ao planejamento urbano institucional, capazes de obter ganhos materiais e simbólicos do ponto de vista dos moradores locais. Essas práticas reúnem elementos que apontam para um campo aberto de possibilidades em relação a uma necessária mudança no planejamento urbano contemporâneo.

Palavras-chave: Planejamento urbano. Insurgência. Urbanização neoliberal. Participação institucional.

\section{Abstract}

Former birthplace of Canadian industrialization, Pointe-Saint-Charles is a neighborhood located near the center of Montreal-QC, in confrontation with an accelerated process of urban revitalization since the 1990s. Faced with this recent process, local grassroots organizations have undertaken diverse struggles, such as the Popular Planning Operations - OPA's, first experienced in 2004. This paper seeks to measure how these practices influence the decision-making power that acts over the local territorial frame. Therefore, we aim to understand these practices constitution as an insurgent planning, as defined by Miraftab $(2009,2016)$ and Purcell (2009). The methodology included the revision of the concept of 
insurgent planning, as well as the collection of primary data such as testimonies, consultation of community documents and technical visits to the referred Montreal's neighborhood. As final considerations, we concluded that the OPA's in Pointe-Saint-Charles constitutes important spaces of counterpower in relation to the institutional urban planning, capable of obtaining material and symbolic gains from the point of view of the local residents. These practices bring together elements that point to an open field of possibilities in relation to a necessary change in contemporary urban planning.

Keywords: Urban planning. Insurgency. Neoliberal urbanization. Institutional participation.

\section{Introdução}

Na última década, cidadãos comuns, ativismos e movimentos sociais urbanos ocuparam os espaços públicos de diferentes cidades ao redor do mundo. De acordo com David Harvey $(2012,2013)$, no Oriente Médio e no norte da África durante a primavera árabe de 2010, na Espanha com os indignados, nos Estados Unidos com o Occupy Wall Street de 2011 ou no Brasil com os protestos de 2013, que tiveram início por uma reivindicação contra o aumento das tarifas de transporte público, essas manifestações possuem entre si algo em comum, pois conformam um campo de ações e de exigências contra a degradação das condições de vida urbana no capitalismo, agravadas por um processo global de neoliberalização, que se tornou hegemônico desde os anos 1970 (ainda que de um modo não homogêneo no tempo e no espaço). Para Harvey, o conceito de "direito à cidade", elaborado por Henri Lefebvre no final dos anos 1960, ressurge com força nesse contexto, não apenas em termos teóricos, mas, sobretudo, na realidade cotidiana, visto ser nos espaços políticos definidos por essas práticas que se revelam novas formas alternativas de se imaginar e transformar a cidade.

É diante desse contexto de neoliberalização das cidades que diferentes formas de "cidadania insurgente" (Holston, 1995) se tornam ainda mais significativas na luta pela democratização da produção do espaço. Se durante a hegemonia do planejamento urbano racionalista (em que o poder decisional esteve fortemente centrado no Estado) limitou-se, em grande medida, a margem de ação para uma produção do espaço com maior autonomia, a participação cidadã, a qual emerge como paradigma da questão urbana no final do século XX, e, portanto, um imperativo na elaboração de políticas públicas em diversas municipalidades em torno do mundo, todavia, não alterou significativamente o poder decisional em relação à cidade. Para Miraftab (2009), a institucionalização da participação no planejamento urbano, ao se inserir no contexto hegemônico do neoliberalismo, não tem necessariamente significado uma produção do espaço mais democrática; ao contrário, a participação em "espaços convidados", criados pelo Estado capitalista, tem servido como um instrumento de "pacificação" dos conflitos e de cooptação instrumental de movimentos e ativismos urbanos.

Pointe-Saint-Charles, antigo bairro industrial da cidade de Montreal em Quebec, possui uma tradição de autogestão em serviços comunitários que remonta ao início dos anos 1970. Localizado próximo ao centro da cidade de Montreal, é nesse território que, diante de um processo acelerado de revitalização urbana nos anos 1990, organizações comunitárias locais têm empreendido diversificadas lutas, como as Operações Populares de Planejamento (OPAs) (Operations Populaires d'Aménagement). Dessa forma, o objetivo deste artigo é compreender de que modo essas práticas se conflagram em um "planejamento insurgente", nos termos descritos por Miraftab $(2009,2016)$. Em que medida essas práticas autoorganizadas de planejamento são capazes de influenciar o poder decisório que atua sobre a trama territorial? Sob quais condições se forma o planejamento insurgente em Pointe-Saint-Charles? Quais são os conflitos, as estratégias utilizadas e os ganhos obtidos pelos cidadãos? De que modo essas práticas autonomistas de planejamento se estabelecem como espaços de contrapoder, os quais pautam alternativas ao planejamento urbano institucional?

Parte-se da hipótese de que as iniciativas de planejamento urbano, impulsionadas pelas organizações populares locais de Pointe-Saint-Charles, preservam um importante grau de autonomia em relação ao quadro institucional estatal, de modo que isso fortalece a construção de uma visão contra-hegemônica 
sobre o desenvolvimento do bairro. Para dar subsídio à hipótese levantada, a metodologia empregada incluiu uma revisão teórica sobre o conceito de planejamento insurgente, a partir da perspectiva radical em relação ao Estado de Miraftab $(2009,2016)$, e crítica ao planejamento participativo/colaborativo de Purcell (2009). De acordo com essa perspectiva, o planejamento insurgente sempre empreende uma visão alternativa, tanto aquela dos empreendedores e investidores imobiliários como de outra forma, transgredindo também os espaços de decisão estabelecidos pelos dispositivos participativos oficiais. Esses "espaços de resistência" são também inovativos, no sentido de que a programação desse planejamento se baseia em uma perspectiva aberta, bastante diferenciada daquela que habitualmente se impôs ao planejamento urbano. Essas práticas ancoram-se ainda em uma forte apropriação simbólica do bairro, apropriação que é sinergicamente ampliada no bojo dessas práticas. As operações populares de planejamento urbano e demais práticas auto-organizadas localmente se opõem ao domínio do valor de troca na produção capitalista da cidade e ao processo de gentrificação consequente ao processo de revitalização urbana, o qual, desde os anos 1990, vem tencionando os moradores de Pointe-Saint-Charles para as bordas da área central de Montreal, processo que seria mais grave se não fosse pela resistência local.

\section{Planejamento insurgente: abordagem teórica}

Na contemporaneidade, a lógica de urbanização neoliberal se tornou o modelo dominante de legalidade da ação estatal em muitas grandes e médias cidades do mundo. Paralelamente, nos últimos 30 anos, a participação de atores da sociedade civil passou a ser imperativa na elaboração de políticas públicas de planejamento urbano, o que significa que não é mais possível pensar em fazer essas políticas sem se cogitar algum tipo de mecanismo aberto de legitimação decisória (Blondiaux \& Sintomer, 2002). Em conjunto, esses dois aspectos congregam uma importante face da lógica que compõe o modelo dominante de produção da cidade contemporânea.

Experiências de insurgência e de resistência ao planejamento urbano conduzido no âmbito das estruturas do Estado constituem-se, todavia, em verdadeiras "exceções à regra", tendo em vista o caráter ideológico que vinculou, historicamente, o ato de planejar a uma atribuição exclusiva do Estado. Não obstante, no atual contexto neoliberal hegemônico na produção da cidade, em que "(...) os direitos de propriedade privada e à taxa de lucro se sobrepõem a todas as outras noções de direito" (Harvey, 2012, p. 73), as práticas insurgentes buscam estabelecer outro tipo de relação com a cidade produzida/em produção. Para autores, como Miraftab $(2009,2016)$ e Purcell $(2009)$, o potencial destacado da noção de planejamento insurgente está em sua capacidade para a transformação do poder das modalidades formais ou práticas institucionalizadas do planejamento urbano contemporâneas.

Conforme aponta Miraftab (2016), vive-se, atualmente, em um momento de crise global que não é apenas uma crise do capitalismo, mas também do planejamento como profissão e como ideia. Para a autora, o planejamento está se defrontando com sua própria crise de identidade e de legitimidade, "(...) uma crise que emerge de sua esquizofrenia profissional, razão pelo que sua própria imagem e ideia da profissão não se encaixam" (p. 363). Ela utiliza o termo "esquizofrenia" para problematizar uma contradição, na qual, segundo descreve, "(...) o planejamento enquanto uma profissão, se auto-enaltece por atender ao bem público, mas os planejadores profissionais frequentemente encontram-se a serviço do bem privado" (Miraftab, 2016, p. 365).

Como busca argumentar, a crise do planejamento leva à necessidade de se formular um novo tipo de planejamento, o qual seja guiado por um "novo significado" e por uma "nova imaginação" associada à produção do espaço. Nesse sentido, ela considera que somente uma virada ontológica na teorização do planejamento seria capaz de conduzir a um rompimento com os postulados que o conduziram a tal crise existencial. Para a autora, essa necessária ruptura na teorização do planejamento requer, em primeiro lugar, o reconhecimento do leque de práticas - para além das sancionadas pelo Estado e pelos poderes corporativos -, nomeadas de práticas insurgentes. Em segundo lugar, ela propõe a descolonização da imaginação relacionada às possibilidades para o futuro em relação à cidade. 0 planejamento insurgente, 
tal qual descreve, não estaria localizado somente no campo imaginativo, pois ele já existe, ao redor do mundo, em práticas nas quais cidadãos se apropriaram dos espaços e planejaram seus próprios futuros. Mas o que o define? Quais são seus princípios? Como esse planejamento insurgente procede a uma ruptura com o planejamento institucional tal qual se conhece?

0 conceito de planejamento insurgente provém de uma tradição radical na teoria de planejamento urbano. A discussão sobre a implicância de formas de auto-organização na produção do espaço baseia-se no conceito de "insurgência cidadã" (insurgent citizenship), inicialmente articulado por James Holston (1995; 2008) e incorporado ao discurso do planejamento por Sandercock (1999), Friedmann (2002) e Miraftab \& Wills, (2005). Para Miraftab (2009), há uma convergência entre esses autores em relação à noção de planejamento insurgente, quando essa noção se alinha com a de um tipo de planejamento radical, o qual resiste, contesta e propõe alternativas aos meios neoliberais de dominação na produção da cidade. Isso não exclui um tipo de resistência às formas e aos mecanismos de participação institucionalizados no Estado, visto que esses espaços participativos são, em geral, largamente definidos de acordo com um conjunto de regras estipuladas pelo próprio Estado capitalista. Tal qual a abordagem metodológica apresentada em Latendresse \& Manzi (2018), considerando os argumentos de Miraftab $(2009,2016)$, as práticas de planejamento insurgente se caracterizariam enquanto "espaços de resistência", conformados por pelo menos três características em comum, constituindo-se em práticas "contra-hegemônicas", "transgressivas" e "imaginativas". São práticas contra-hegemônicas, pois se opõem em alguma medida ao poder heterônomo centralizado no Estado capitalista, sobretudo em sua versão neoliberal; transgressivas (no tempo, no espaço e na ação), pois ancoram-se em uma consciência historicizada, a qual, em termos de ativismo, não se atém aos limites das fronteiras nacionais nem se contentam em obedecer às regras estipuladas pelo Estado; e imaginativas, pois, baseadas no idealismo de uma sociedade justa, propõem formas autênticas de representação do espaço vivido a partir dos sentidos e das experiências do cotidiano dos cidadãos. Por fim, esse planejamento insurgente difere-se do planejamento institucional, pois não se baseia na "inclusão", por meio de uma melhor representação de técnicos especialistas ou de políticos, mas sim em uma "(...) inclusão autodeterminada, na qual os direitos das pessoas são reais e praticados" (Miraftab, 2016, p. 368).

A partir dessas considerações, a autora distingue dois pontos críticos na análise referente ao planejamento insurgente. Conforme aponta, essa análise deve levar em consideração e distinguir os "espaços convidados" (enquanto formas selecionadas de ação dos cidadãos e suas organizações pelos grupos dominantes) dos "espaços inventados" (enquanto espaços que o Estado, as corporações e a mídia dominante buscam sistematicamente colocar no ostracismo e criminalizar, considerando somente os primeiros como espaços válidos de ação). Ambos os espaços se encontram em uma relação dialética, de interação mútua e não binária, de modo que as práticas insurgentes de planejamento frequentemente têm de se mover entre aqueles espaços convidados, conforme as necessidades específicas de cada luta. Considerando os riscos que a participação institucional representa em termos de cooptação de movimentos e ativismos urbanos, nos quais se inscrevem as práticas de planejamento insurgente, a autora adverte:

(...) devemos observar que uma construção binária de espaços convidados e inventados arrisca uma concepção fixa equivocada de estabilidade em cada espaço. Essa construção binária desconsidera a flexibilidade e a natureza inovadora do capitalismo e como ele se desdobra sobre o que quer que esteja a sua margem e busca incorporar o que quer que possa constituir uma ameaça a ele. 0 que hoje é uma alternativa pode se tornar uma tendência dominante e despolitizada pela repressão e cooptação amanhã, com sua força transformadora minada (Miraftab, 2016, p. 369).

O contexto neoliberal utiliza a ideia de "inclusão" como álibi para a exclusão e para a normalização da dominação. De acordo com Miraftab (2016), a falência do planejamento participativo ("inclusivo") tem forçado a necessidade de repensar os parâmetros ontológicos das teorizações e práticas de planejamento. Para tal, ela percebe ser fundamental a recentralização da ideia de justiça social na teorização do planejamento. Segundo a autora aponta, a partir de Rawls (1971) e Young (1990), os ativistas de práticas insurgentes vêm modificando a ideia tradicional de justiça enquanto igualdade de direitos para a noção 
da justiça baseada no reconhecimento das diferenças e de suas políticas; eles entendem não ser suficiente conceder direitos individuais e um tratamento igualitário (como advoga a filosofia política liberal da justiça) e, ao mesmo tempo, lutam pelo reconhecimento das formas de opressão baseadas em grupos. Tal compreensão da justiça discute sobre a inclusão - focado na representação política que concede por vezes espaços à participação institucional - passar a um debate para a autodeterminação (Miraftab, 2016). Isso tem importantes implicações para o planejamento, porque rompe ontologicamente com a noção liberal de inclusão que guiou o planejamento profissional durante boa parte do século XX.

As críticas apresentadas chamam a atenção para a necessidade de um rompimento radical com o planejamento urbano inclusivo ou participativo. 0 planejamento insurgente desempenha um papel relevante na mudança do poder centrado nas instituições, na mídia dominante, no mercado e no Estado, ao demonstrar a não exclusividade desses "centros" como formas de poder. Conforme o planejamento insurgente descentraliza o papel da representação política, ele muda também o sujeito-alvo de sua teorização: do planejador e de seu campo de ideias para a prática social. Para o planejamento insurgente, os planejadores profissionais não são mais do que atores que compõem o campo de ação do planejamento; este último é um campo de conhecimento que é, a todo momento, questionável (Miraftab, 2016).

Para Mark Purcell (2009), as críticas existentes ao planejamento comunicativo ou colaborativo se tornam mais urgentes no contexto da neoliberalização existente. Para o autor, a neoliberalização é compreendida como um projeto para instalar a lógica de mercado e a disciplina competitiva enquanto premissas dominantes em políticas públicas urbanas. Sob essas condições, as práticas decisionais dessas políticas não alteram fundamentalmente relações de poder existentes, ao passo que elas conferem um alto grau de legitimidade política às decisões tomadas em seu âmbito. 0 planejamento participativo institucionalizado providencia um meio extremamente atrativo para os neoliberais manterem a hegemonia enquanto garantem a estabilidade política; essa participação institucional, portanto, não é capaz de confrontar a neoliberalização. Mais promissoras, de acordo com o autor, são as mobilizações contra-hegemônicas, cujas metas não são neutralizar as relações de poder (o que seria um reflexo da participação institucional), mas transformá-las. Ele argumenta ser necessário uma alternativa democrática não enraizada na tradição liberal ou mesmo nas teorias deliberativas.

Segundo argumenta Purcell (2009), o problema com abordagens, como o Communicative planning (Healey, 1996; Innes, 1995), o Argumentative planning (Fischer \& Forester, 1993) ou ainda o Deliberative planning (Forester, 1999), é que tais enfoques tendem a diminuir o teor político ou conflitivo do planejamento. $O$ ideal comunicativo busca progressivamente minimizar as diferenças e enfatizar os "interesses comuns" entre os atores. Tais abordagens de planejamento apenas mascaram os conflitos e não são capazes de transcendê-los, mesmo a curto prazo. Tal mascaramento “(...) pode ser uma ferramenta extremamente eficaz para os interesses neoliberais porque relações de poder ocultas podem permanecer intocadas enquanto uma significante legitimidade política é conferida" (Purcell, 2009, p. 153 - tradução nossa). Embasado em Laclau \& Mouffe (1985), Purcell coloca que a política não pode ser considerada como uma busca pelo entendimento intersubjetivo embasada em consensos: a política é essencial e necessariamente uma luta por hegemonia. 0 objetivo de um planejamento radical, portanto, não deve ser o de desenvolver, a priori, processos para controlar, neutralizar ou eliminar relações conflituosas de poder; ao contrário, seu objetivo deve ser o de transformar essas relações, o que inclui a mobilização do poder para o fortalecimento de lutas contra-hegemônicas e o estabelecimento de novas hegemonias.

Para Purcell (2009), na tradição do planejamento, a construção de consensos tem representado um risco ainda mais grave, que é o de dar suporte a neoliberalização. Se, na teoria da ação comunicativa de Habermas (1985), é desejável que cidadãos se encontrem em condições ideais de fala; que as diferenças de poder entre os participantes sejam neutralizadas por mecanismos deliberativos; que todos os participantes afetados pelas decisões participem de modo significativo; que todos tenham a mesma chance de participar na deliberação; que cada um deve dispor-se de modo empático com argumentos de outros; e que todos devem esperar atingir o bem comum acima de seus interesses individuais, constituindo a base do que Habermas chama de comunicação não distorcida (ainda que essas formas de comunicação se constituam em um ideal, como o próprio Habermas pondera), Mouffe (2000) argumenta 
que a linguagem é sempre política e distorcida pelo poder, sendo essas distorções intrínsecas à linguagem e necessárias para tornar a comunicação inteligível (Purcell, 2009, p. 150). A perspectiva habermasiana da ação comunicativa é contestada por autores, como Laclau (1996) e Mouffe $(2002,2005)$, os quais, a partir de uma perspectiva foucaultiana, consideram o poder como relacional, existente e operante somente na relação entre indivíduos ou grupos. Desse modo, as relações de poder, embutidas nas falas e nas argumentações frequentes em processos de participação institucional, não são, na perspectiva defendida por Purcell, uma qualidade alienável, a qual pode ser temporariamente neutralizada por técnicas comunicativas. Como aponta o autor, qualquer tentativa de neutralizar o poder por um tipo de mediação é em si uma imposição particular de relações de poder (Purcell, 2009, p. 151). A forte tradição associativa em Pointe-Saint-Charles, através das décadas, vem consolidando um terreno fértil para o surgimento de práticas autonomistas e inovativas que confrontam uma série de elementos da ordem vigente ligada à urbanização.

\section{Tradição associativa em Pointe-Saint-Charles}

Pointe-Saint-Charles é um dos cinco bairros que fazem parte do distrito Sudoeste (Sud-Ouest), situado próximo ao centro da cidade de Montreal. Antigo bairro operário e berço da industrialização montrealesa e canadense, já abrigou uma população de aproximadamente 30 mil pessoas em 1931, quando as usinas situadas nas bordas do canal de Lachine empregavam uma boa parte dessa população - atualmente, a população de Pointe-Saint-Charles é de cerca de 14 mil habitantes, menos da metade daquele total (Triollet, 2013). Em 1968, a abertura da via marítima de Saint-Laurent e o fechamento do canal de Lachine à navegação impulsionaram definitivamente o processo de desindustrialização em Pointe-SaintCharles, o que resultou no abandono de dezenas de usinas e indústrias na localidade. Diante das dificuldades, a população entrou em êxodo massivo na década de 1970. Consequentemente, o espaço urbano passou a revelar diversos problemas, como poucos empregos, baixos salários, déficit habitacional, carências em saúde, segurança e educação, usinas e de áreas públicas abandonadas, além dos terrenos contaminados pelos anos de uso da atividade ferroviária. A Figura 1 ressalta espaços de aceleradas transformações urbanas em Pointe-Saint-Charles, espaços que foram simbolicamente apropriados por moradores e organismos comunitários como a Action-Gardien.

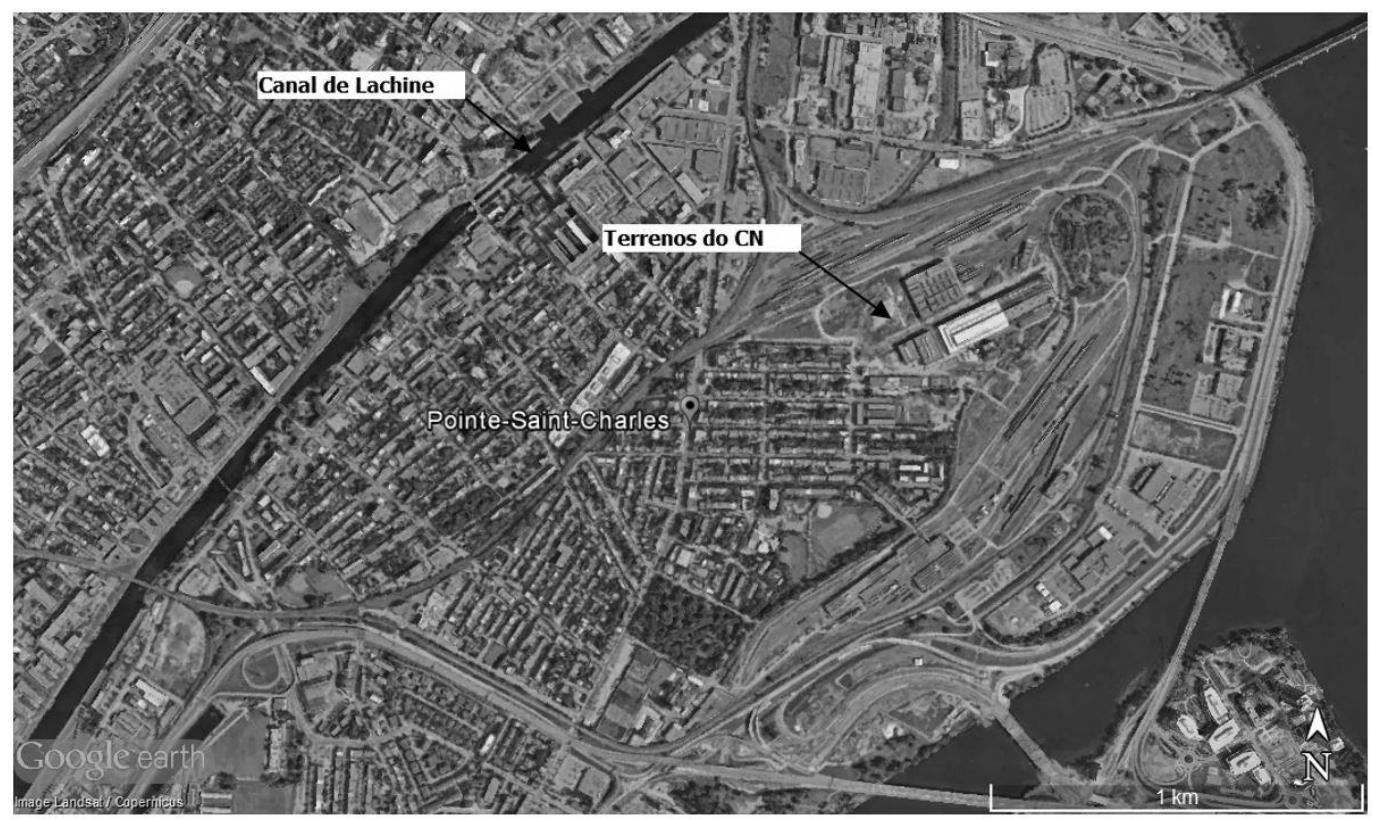

Figura 1 - Localização dos principais conflitos abordados no estudo de caso em Pointe-Saint-Charles. Fonte: imagem do Google Earth modificada pelos autores. 
Pointe-Saint-Charles é um território de uma tradição auto-organizativa de longa data e que remonta a calorosas greves e organização sindical, no período entre o final do século XIX até meados dos anos de 1960. Também foi no final dessa década que estudantes e professores da Universidade Mcgill e associações de caridade de igrejas criaram os primeiros comitês de cidadãos para enfrentar as dificuldades ligadas ao declínio das condições de vida locais, decorrentes, sobretudo, do desemprego de um setor industrial até então bastante vigoroso. A dinâmica emergente da organização comunitária nos anos 1970 incluiria intervenções autônomas nas áreas da saúde, educação, habitação, assistência jurídica e econômica, entre outros segmentos, conformando um espaço que passou a contar com a presença de um significativo capital social, o qual, perpassando décadas, alcança o ativismo comunitário mais recente no bairro.

Na virada dos anos 1970, surgiu uma série de iniciativas pautadas na auto-organização dos moradores do bairro. Para superar as dificuldades, a Clínica Comunitária de Pointe-Saint-Charles foi criada, servindo, posteriormente, de modelo para a implementação da rede de Centros Locais de Serviços Comunitários (CLSC), do governo provincial do Quebec. Atualmente, a Clínica é financiada pelo governo provincial, mas manteve-se sendo inteiramente gerida por cidadãos ligados a organizações comunitárias do bairro, uma exceção dentro do modelo provincial. PointeSaint-Charles é também pioneiro no plano dos serviços jurídicos comunitários em Quebec, servindo também de modelo para a criação da rede quebequense de escritórios de ajuda jurídica. De modo inovador no território, o primeiro centro de serviços jurídicos de Quebec foi instalado em Pointe-Saint-Charles em 1972, com o objetivo de oferecer gratuitamente serviços jurídicos a pessoas desfavorecidas. Outra iniciativa local que parte da auto-organização cidadã é o Programa Econômico de Pointe-Saint-Charles (PEP), fundado em 1984 e que se tornou, em 1989, o Reagrupamento Econômico e Social do Sudoeste (RESO). O RESO encontra-se em atividade atualmente e oferece apoio para a formação profissional e a inserção no mercado de trabalho, especialmente de jovens e imigrantes.

Chama também atenção o grande número de cooperativas habitacionais localizadas no bairro. Em 2005, Pointe-Saint-Charles agrupava uma grande quantidade de cooperativas habitacionais em Montreal, com mais de 50 cooperativas de habitação e mais de 1.200 unidades habitacionais voltadas para a baixa renda. A primeira cooperativa de habitação em Quebec foi criada em PointeSaint-Charles em 1971 (Loge-peuple). Mesmo tendo desaparecido após anos de uma existência difícil, a iniciativa serviu de inspiração para uma série de outras cooperativas autogeridas que apareceram em Montreal, e mesmo em Quebec, em décadas posteriores. Para Triollet (2013: 139), embora o grande número de cooperativas habitacionais tenha trazido melhorias concretas para o bairro, o acesso amplo à moradia continua sendo um desafio para essas cooperativas, em virtude, dentre outros fatores, da ameaça do fim dos programas federais de subvenção, da raridade de terrenos disponíveis para novas unidades e do baixo grau de inclusão de habitação social nos novos empreendimentos, esta última é uma demanda frequente de organizações comunitárias, como a Action-Gardien.

A mesa de concertação Action-Gardien foi criada em 1981, a partir da vontade de integrantes dos organismos comunitários em reunir esforços coletivos para superar as dificuldades e buscar a melhoria das condições de vida do bairro. A Action-Gardien, atualmente, reúne cerca de 25 organismos locais, que animam um espaço onde se estabelecem mobilizações para promover interesses e direitos dos habitantes do bairro, particularmente daqueles menos favorecidos economicamente. Em 1986, a Action-Gardien desenvolveu, em colaboração com as organizações comunitárias locais, seu primeiro plano de planejamento local: Des choix pour la Pointe, um quartier à améliorer, une population à respecter, em resposta ao plano lançado em 1984 pela administração municipal de Jean Drapeau (típico prefeito "urbanista" que governou Montreal entre 1954-1957 e 1960-1986). Os membros da Action-Gardien se reúnem uma vez por mês em assembleia para fazer avançar os dossiês diversos associados à qualidade de vida, tematizando, 
problematizando e debatendo, de forma autogestionária e participativa, as questões inerentes ao desenvolvimento e planejamento urbano do bairro e de seu entorno.

As questões do desenvolvimento do planejamento urbano têm estado a todo tempo no centro das preocupações dos organismos comunitários do bairro, como a Clínica Comunitária e a Acion-Gardien. A partir de meados dos anos 2000, com a imposição de um processo de revitalização urbana nas bordas do canal de Lachine, a qual incluiu a conversão das antigas usinas em condomínios de luxo e grandes projetos recreativos e turísticos (elaborados por promotores privados e públicos), a Action-Gardien passou a concentrar seus esforços na problematização do tipo de desenvolvimento urbano almejado para o bairro e a elaborar propostas de intervenção que reúnem as opiniões e as considerações dos moradores. Nos últimos 20 anos, as principais mobilizações que marcaram a atuação da Action-Gardien em Pointe-Saint-Charles foram: i) a elaboração dos dez princípios de desenvolvimento do canal de Lachine, no ano 2000; ii) a organização da primeira Opération Populaire d'Aménagement (OPA), em 2004; iii) a mobilização contra o projeto de mudança do Cassino para Pointe-Saint-Charles, em 2005, e a segunda OPA sobre o projeto para os antigos terrenos do CN, luta que se desenvolveu entre 2007 e 2012; iv) um fórum de segurança alimentar e uma mobilização pela melhoria do transporte comum, em 2010; v) um estudo sobre a habitação social e a evolução das áreas construídas em colaboração com o coletivo RIL (Regroupement Information Logement), seguido de um fórum para a adoção de um plano de ação sobre habitação, em 2012; vi) mobilizações sobre o projeto para o setor Bridge-Bonaventure, em 2014.

\section{Transformações urbanas recentes em Pointe-Saint-Charles}

De acordo com Triollet (2013, p. 137), as imediações do canal de Lachine foram, durante mais de 125 anos, um lugar de trabalho para a população do distrito Sudoeste de Montreal. Ao final dos anos de 1990, os terrenos e as antigas usinas abandonadas na década de 1960, estagnados pelo desinteresse econômico de cerca de três décadas, passaram a sofrer um processo intenso de revalorização, sendo cobiçados pelos promotores e investidores imobiliários. Atraídos pela possibilidade de investimentos lucrativos nos imensos terrenos localizados próximos ao centro da cidade, esses empreendedores lançaram mão de extensos projetos e iniciaram um processo de requalificação urbana em Pointe-Saint-Charles. A elitização e o aumento dos valores dos aluguéis deram início a um processo de gentrificação, no qual ocorreu, progressivamente, a substituição dos moradores originais por novos residentes de classe média ou alta.

Em 1998, a prefeitura de Montreal lançou um vasto projeto de reabertura do canal de Lachine à navegação de lazer e, com isso, intensificou a valorização de suas margens. Cerca de 80 milhões de dólares de fundos públicos foram investidos, sendo a maior parte desse montante destinada para beneficiar as infraestruturas ligadas aos empreendimentos imobiliários (Triollet, 2013). As bordas do canal Lachine foram tomadas por um processo de privatização, o que incluiu o fechamento com grades e senhas exclusivas aos moradores dos novos condomínios para o acesso aos trapiches e às embarcações (ver Figura 2). Os edifícios industriais foram convertidos em lofts, e os edifícios obsoletos foram destruídos, enquanto o preço dos terrenos vagos aumentou significativamente. Esse domínio do capital imobiliário e turístico ocorreu sobre porções do espaço que simbolicamente foram apropriadas, através dos anos, pelos cidadãos de Pointe-Saint-Charles, em decorrência, sobretudo, de sua importância para os moradores, muitos dos quais eram descendentes diretos dos trabalhadores das antigas usinas locais. Esses moradores também reconheceram a importância histórica do antigo sítio industrial e pretendiam mantê-lo enquanto uma zona de empregos, voltados para as necessidades do bairro. 

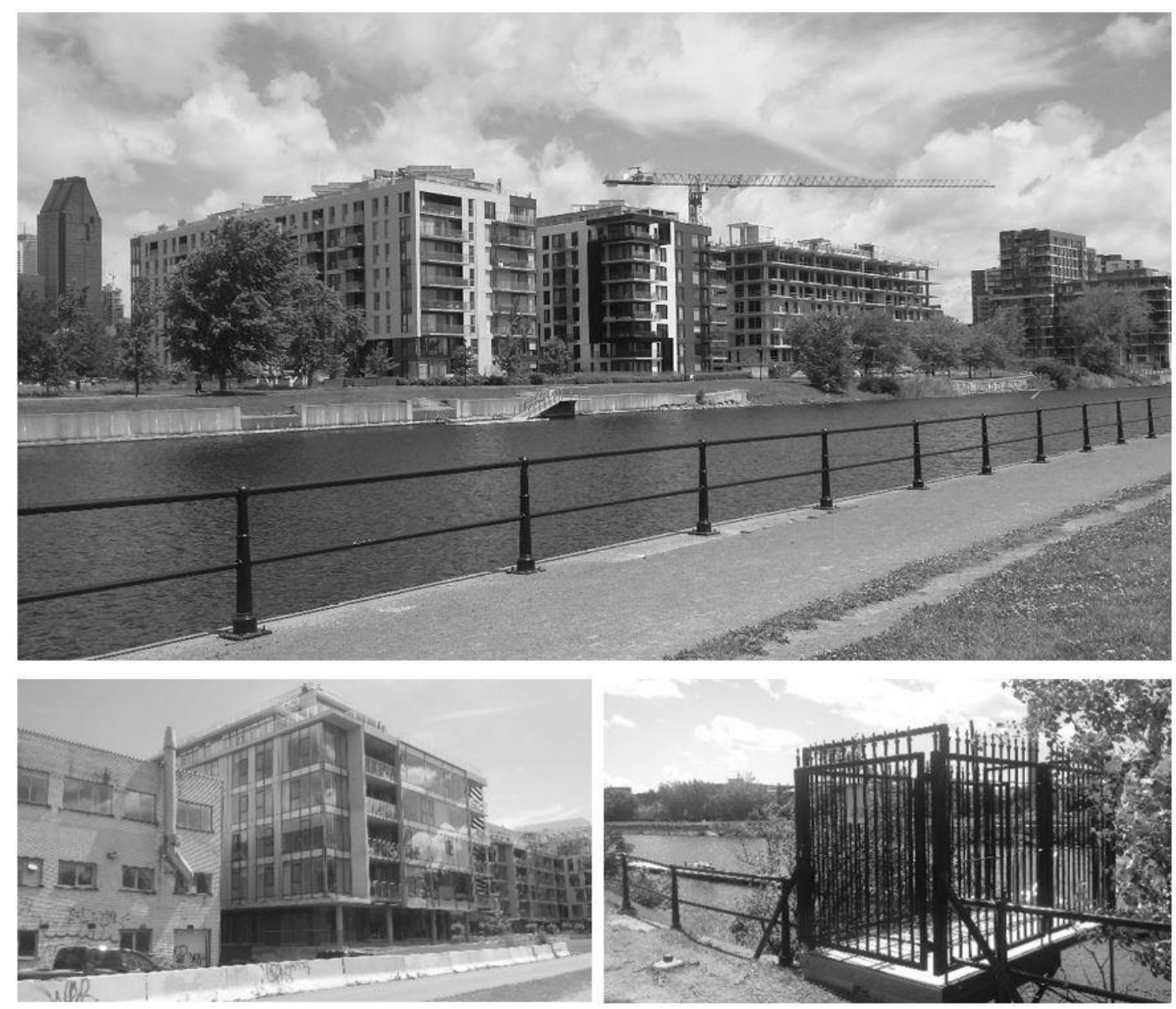

Figura 2 - Privatização do acesso público ao canal de Lachine. Fonte: arquivo pessoal dos autores (2017).

Segundo Grenier (2008), o antigo corredor industrial “(...) é hoje um verdadeiro eixo recreoturístico de água e de verde que se constitui num catalizador de um processo de revitalização urbana que afeta todo o Sudoeste da Ilha de Montreal" (Grenier, 2008, p. 18 tradução nossa). De acordo com Gravel (2012), o Parcs Canada (agência departamental do governo canadense que administra os parques no país) planejou um parque linear ao longo de todo o canal de Lachine. Foi assim que a revitalização se iniciou, tomando forma pela reconversão de indústrias em proveito de vastos projetos residenciais. Os novos empreendimentos imobiliários têm suas fachadas de frente para o canal, com os fundos voltados para Pointe-Saint-Charles. As propagandas e as estratégias de marketing anunciam as vantagens de morar próximo ao centro da cidade, em novos padrões arquitetônicos e estilos de vida contrastantes que negligenciam os espaços de vida no bairro.

O processo de revitalização no canal de Lachine reflete uma visão empresarialista da prefeitura para a cidade, presente em slogans, como "cidade internacional" ou "cidade multimídia". A visão da elite política e econômica pelo crescimento da cidade, representada pela Société du Havre ${ }^{1}$, havia apostado na requalificação dos quarteirões centrais e próximos a centro, com o objetivo de atrair maiores retornos sobre seus investimentos. De acordo com Triollet (2013), estrategicamente, esse relance econômico é frequentemente apresentado como "estruturante" pelos poderes públicos, "(...) sem todavia se interrogar sobre os impactos destas transformações na identidade do quarteirão e suas populações de baixa e modesta renda" (Triollet, 2013, p. 130 - tradução nossa). 0 modelo de desenvolvimento impulsionado pelos interesses do mercado contrasta com as reais

\footnotetext{
${ }^{1}$ Corporação privada investidora do projeto, criada em 2002 e extinta em 2013, por conta de pressões populares e processos judiciais com acusações de desvios de grandes somas de dinheiro.
} 
necessidades do cotidiano dos moradores, os quais, por intermédio de suas organizações, reúnem demandas e proposições que conformam uma visão de conjunto, que é, ao mesmo tempo, contrahegemônica, transgressiva e imaginativa. É o caso das Opérations Populaires d'Aménagement de Pointe-Saint-Charles.

\section{Um planejamento insurgente em Pointe-Saint-Charles}

No início da década de 2000, o processo de requalificação urbana "tomou conta" da parte norte de Pointe-Saint-Charles, dando continuidade a um processo já consolidado em Griffintown, bairro vizinho localizado na outra margem do canal de Lachine. Buscando antecipar-se ao andamento desse processo sobre Pointe-Saint-Charles, os moradores locais se organizaram para reivindicar, entre outros pontos, a manutenção de características arquitetônicas e urbanísticas do bairro e, sobretudo, a permanência de seus moradores no local. A permanência do zoneamento industrial nas imediações do canal de Lachine era uma das requisições dos moradores e organizações, por exemplo, a Action-Gardien, como forma de evitar a especulação fundiária e imobiliária e de enfrentar o problema do desemprego. Segundo depoimentos ${ }^{2}$, contudo, diante da força política dos empreendedores, essa batalha foi considerada como perdida pelos moradores de Pointe-Saint-Charles, que hoje se esforçam para monitorar as poucas áreas restantes nas bordas do canal. Outras questões, todavia, continuam a ser pautadas pelas práticas insurgentes de planejamento, as quais disputam o poder decisional sobre o território com os projetos de empreendedores e planos da administração pública. É o caso da primeira e segunda OPA.

Foi durante a rodada de consultas para revisão do Plano de Urbanismo de Montreal para o distrito Sudoeste, em 2004, e, em virtude das críticas endereçadas a esse processo, que a Action-Gardien e a Clínica Comunitária de Pointe-Saint-Charles decidiram realizar uma experiência auto-organizada de planejamento urbano no bairro. A primeira Opération Populaire d'Aménagement se constituiu em um exercício participativo em planejamento urbano, voltado para a identificação dos problemas e a elaboração de propostas baseadas no conhecimento local dos moradores (ver Figura 3). Nessa primeira OPA, foram realizados diagnóstico e exercícios participativos sobre o terreno, com saídas de observação e organização de trabalhos em diferentes comissões. Cerca de uma centena de moradores engajados, apoiados por profissionais voluntários, como geógrafos, arquitetos e urbanistas ${ }^{3}$, além de assessores remunerados (por meio do fundo de saúde ${ }^{4}$ ), examinou o bairro em detalhes, nomeando problemas, identificando pistas e soluções, muitas das quais foram, posteriormente, mapeadas na proposta entregue ao Office de Consultation Publique de Montreal (OCPM), órgão que, desde sua fundação em 2002, é responsável por realizar consultas públicas sobre os projetos de urbanismo de maior impacto na cidade de Montreal (Paré, 2008). Desde então, as OPAs de Pointe-Saint-Charles se estabeleceram como uma prática auto-organizada para a definição de prioridades urbanas debatidas na comunidade e que busca assegurar que a opinião coletiva seja incorporada ao processo decisional do planejamento urbano do bairro.

\footnotetext{
2 Foram realizadas, ao todo, sete entrevistas com atores-chave ligados ao processo de planejamento urbano em Pointe-Saint-Charles.

${ }^{3}$ Uma participação voluntária importante foi a do escritório de arquitetura L'Oeuf, que apoiou tecnicamente as oficinas de desenho urbano, conduzidas pelos militantes das associações locais.

${ }^{4}$ Uma parte do funcionamento das mesas de concertação em Quebec, como é o caso da Action-Gardien, é proveniente dos fundos provinciais de saúde. A questão da saúde preventiva, associada à vida urbana, é vista como prioridade em Quebec, o que explica em partes o interesse de instituições de governo em financiar a iniciativa das mesas de concertação. Esses fundos servem para estrutura, materiais e salário de alguns dos militantes das mesas.
} 

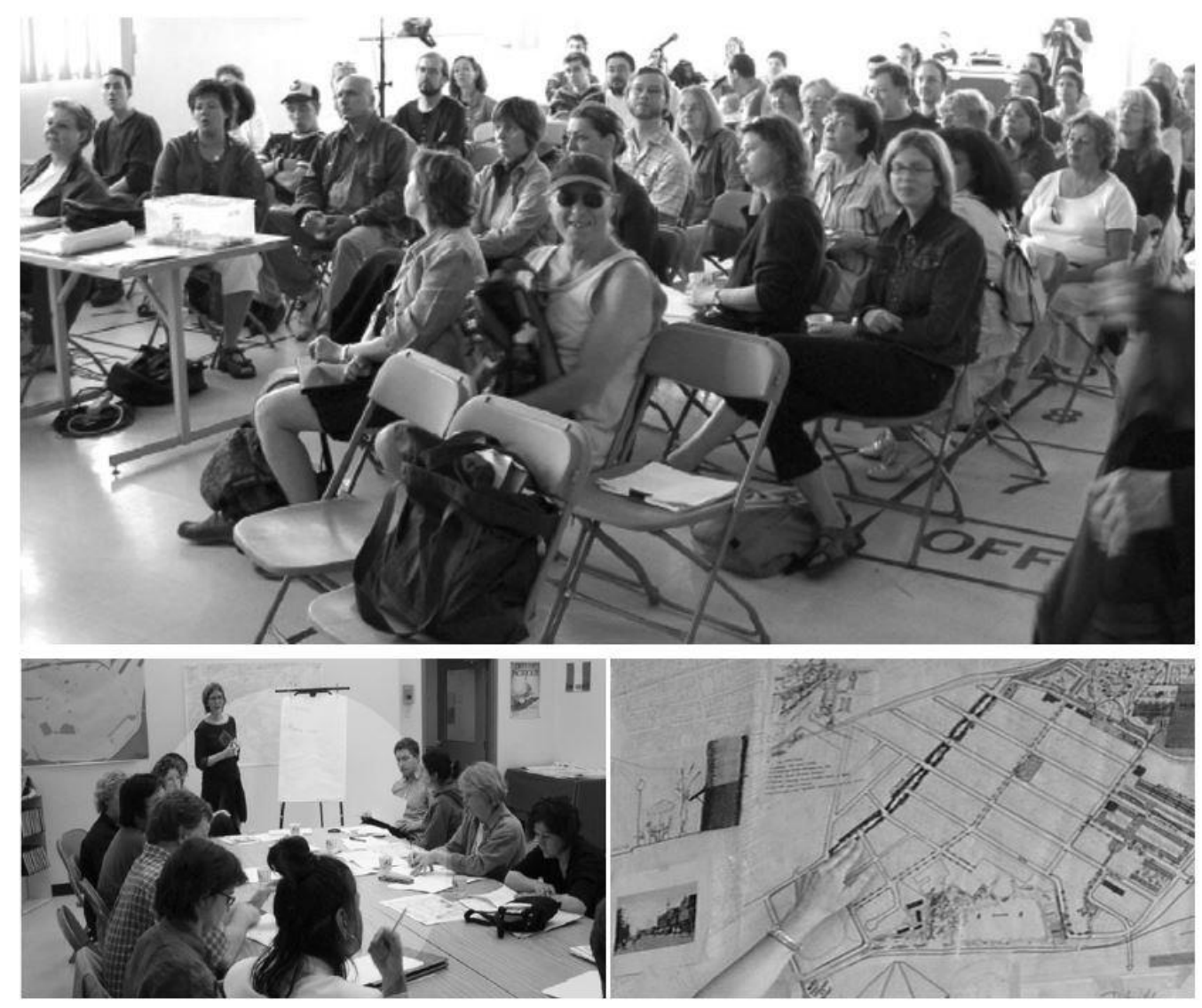

Figura 3 - Primeira OPA de Pointe-Saint-Charles em 2004. Fonte: fotos de Marie-Pierre Paquin-Boutin.

De acordo com o relatório de resultados dessa OPA, elaborado pelos membros da Action-Gardien (2005), a primeira reunião pública ocorreu no dia 20 de abril daquele ano, ocasião em que se discutiu a história do desenvolvimento urbano do bairro e foram dados encaminhamentos sobre a experiência de planejamento a ser realizado. Foram apresentados os quatro setores da OPA e explicou-se, em detalhes, como se desenvolveriam os trabalhos do final de semana de 4, 5, e 6 de junho. Ao final desse encontro, cada cidadão pôde escolher fazer parte de uma equipe de setor, sendo concedidos cartas do bairro e lápis de cor, acompanhados de um modo de trabalho e de um questionário. Cada participante disporia de duas semanas para caminhar pelo bairro e identificar os locais que gostava de frequentar, os trajetos que tomava, as atividades que exercia, os lugares ou os aspectos a melhorar e as soluções que propunha. As pessoas podiam realizar esse exercício individualmente ou em grupo.

Na noite de sexta-feira, 4 de junho de 2004, ocorreu a exposição dos resultados desse exercício. Um retrato do bairro, em relação aos seus aspectos positivos e às suas demandas, buscou ser construído a partir das observações feitas. As equipes de cada setor deviam, a partir das informações levantadas, estabelecer uma ordem de prioridade e preparar o itinerário do dia seguinte. No sábado de manhã, as equipes interpretaram os seus respectivos setores, acompanhadas pela equipe de assessores e de profissionais voluntários. Durante à tarde de sábado e na manhã do dia seguinte, ocorreram os ateliês de discussão com os temas definidos. Enquanto os moradores comuns participavam dos ateliês, o pessoal técnico preparava as esquetes e os planos. As pausas eram numerosas para permitir que os participantes dos ateliês se juntassem ao pessoal técnico para acompanhar a progressão dos desenhos e fazer comentários.

0 exercício do final de semana terminou no domingo à tarde, com uma apresentação ao conjunto de participantes, das proposições elencadas pelas equipes de cada setor. Os participantes podiam então expressar suas opiniões, incorporar comentários e precisar os projetos. Como resultado, mais de 
150 propostas foram elencadas, focadas no melhoramento das condições urbanas locais. Essas propostas estiveram divididas em oito grandes temas: especulação, habitação, comércios e serviços; terrenos vagos; parques e equipamentos coletivos; questões de segurança; atividade ferroviária; circulação de veículos, ciclovias e calçadas; transporte coletivo; limpeza e embelezamento. Um ano mais tarde, a primeira OPA prosseguia por meio de seus encaminhamentos levados adiante em comitês de trabalho. Constituídos por moradores e organismos comunitários, esses comitês aprofundaram as reflexões iniciais e buscaram a operacionalização das demandas que foram inicialmente definidas. Uma segunda OPA ocorreu nos anos seguintes, e, como resultado, diferentes relatórios foram entregues ao OCPM em anos posteriores.

Entre as lutas que mobilizaram mais pessoas no bairro e por mais tempo, estão a destinação dos antigos terrenos pertencentes ao Canadien National ${ }^{5}(\mathrm{CN})$, a maior companhia ferroviária do Canadá, privatizada no início dos anos 1990. Esses terrenos foram adquiridos pela soma de um dólar canadense, pelo Grupo Mach, em 2002, o qual tinha, inicialmente, a intenção de revender os terrenos para grupos empresariais do Cirque du Solei e do Cassino de Montreal, após descontaminá-los pelo uso da atividade ferroviária (tarefa que lhes custaria um montante de 12 milhões de dólares canadenses). Devido às pressões populares emergentes de Pointe-Saint-Charles, tal projeto não perseverou, e o Grupo Mach passou a elaborar uma segunda proposta de exploração da área, com projetos de empreendimentos imobiliários (Cayer, 2013).

Entre 2005 e 2006, a luta popular saiu vitoriosa contra o projeto de construção do enorme complexo recreoturístico, o qual seria instalado sobre os antigos terrenos do $\mathrm{CN}$ e que se inseria nos objetivos de requalificação urbana, conduzido pela associação entre a prefeitura e os setores empresariais sobre diversos setores do distrito Sudoeste de Montreal. 0 megaprojeto previa a realocação do Cassino de Montreal, de sua localização atual na Île Notre Dame para Pointe-Saint-Charles, além de um hotel de 300 quartos, uma sala de espetáculos para 2.500 pessoas e um centro de feiras comerciais internacional. Ele incluía ainda uma conexão de trem que ligaria o centro de feiras comerciais internacional a outros equipamentos turísticos, com a estação final no que deveria ser, na visão dos empreendedores e da prefeitura, a nova localização do Cassino. Após cerca de oito meses de manifestações públicas e de pressões públicas que ocorreram dentro e fora dos espaços institucionais, os promotores resolveram abandonar o projeto. Para Cayer (2013), a vitória do ativismo social nessa disputa renovou as esperanças ao propor um desenvolvimento mais humano para a localidade, pautado nas necessidades e nos desejos dos moradores.

Em 2007, em resposta aos novos projetos imobiliários anunciados pelo Grupo Mach e antecipando-se ao processo de consulta que seria posteriormente conduzido pelo OCPM, a Action-Gardien organizou, de modo autônomo, uma grande consulta popular sobre o destino dos terrenos do CN. Depois de meses de preparação, incluindo visitas aos terrenos, exposição com planos e maquetes, em maio daquele ano, a Action-Gardien realizou uma nova OPA e apresentou um relatório de resultados em dezembro. A OPA de 2007 foi uma prática participativa de duração de um fim de semana, a qual teve como objetivo imaginar e ilustrar as proposições locais para os terrenos do $\mathrm{CN}$, contando novamente com a participação de profissionais voluntários.

Segundo o relatório final de resultados da OPA elaborado e entregue ao OCPM em 2009, e de acordo com Triollet (2013), de modo semelhante à primeira, essa OPA definiu os diferentes usos do espaço, segundo as necessidades locais: habitação, emprego, parques e espaços verdes, serviços e comércios de proximidade, equipamentos coletivos, transportes públicos, ciclovias e calçadas. Os grupos de participantes foram divididos para argumentar sobre os diferentes temas, e vários desenhos foram feitos pelos profissionais voluntários a partir das propostas dos moradores participantes. Além da manutenção

\footnotetext{
${ }^{5}$ Os antigos terrenos do Canadien National compreendem um quarto da superfície total de Pointe-Saint-Charles. Com 35 hectares e comportando 12 grandes edifícios industriais construídos entre 1914 e 1957, entre outras construções menores, esses terrenos estão situados em uma localização estratégica, próximos do canal de Lachine e do centro histórico de Montreal. Como diversas gerações trabalharam nos ateliês ferroviários do Canadien National, os terrenos e suas instalações guardam as muitas memórias do bairro, sendo por esse motivo que os moradores de Pointe-Saint-Charles se apropriaram desse espaço.
} 
do zoneamento industrial, da criação de novos empregos, do aumento da oferta de serviços (sobretudo alimentares), das melhorias no transporte público, do acesso ao canal de Lachine e ao rio Saint-Laurent, dentre outros temas, os resultados dessa OPA demonstraram uma vontade coletiva dos moradores de Pointe-Saint-Charles: a de que o projeto para os terrenos do CN deveria contemplar a preservação das características do bairro, com o prolongamento das quadras residenciais, em padrões arquitetônicos e urbanísticos que não destoassem dos já existentes no bairro (ver Figura 4).

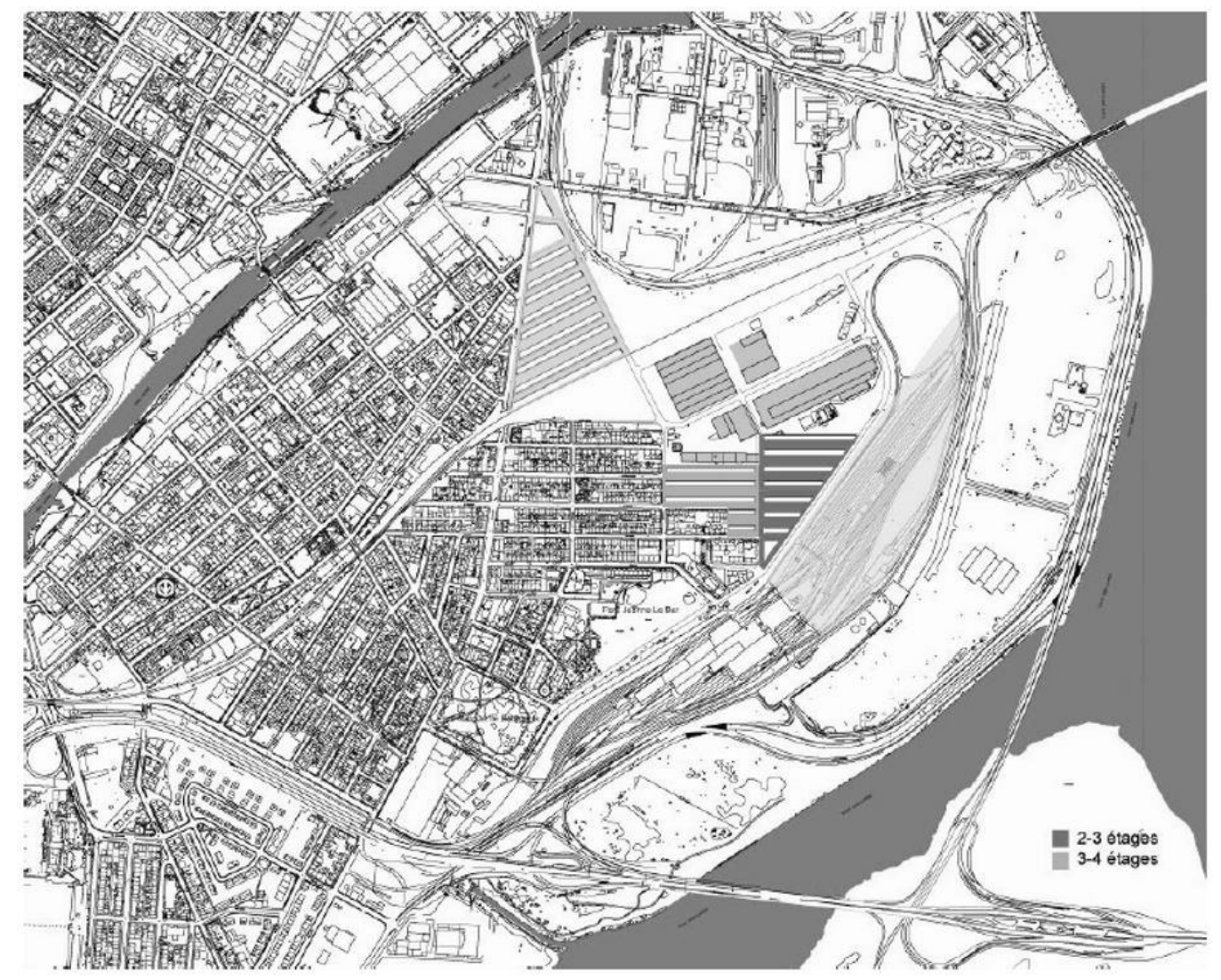

Figura 4 - Projeto participativo com o prolongamento das quadras residenciais sobre os terrenos do CN. Fonte: Relatório de resultados da OPA de Pointe-Saint-Charles (Action-Gardien, 2009).

Em virtude das exigências da realização de consultas públicas na província quebequense, com a Loi sur L'aménagement et L'urbanisme (lei aprovada em 1979), e desde a criação do Office de Consultation Publique de Montreal em 2002, mas também em razão da grande mobilização local por causa do projeto dos promotores, a cidade reagiu e criou seu próprio processo de consulta pública, conduzido pelo OCPM. Em setembro de 2008, sob demanda do distrito Sudoeste e do comitê executivo de Montreal, o OCPM recebeu um mandato para a realização de audiências públicas sobre os antigos terrenos do CN. Os grupos comunitários, reunidos em torno da Action-Gardien, participaram ativamente desse processo. Dois relatórios de recomendações foram elaborados pelo OCPM e entregues às autoridades municipais e do distrito Sudoeste em março e em dezembro de 2009.

De acordo com o relatório de resultados da OPA (Action-Gardien, 2009), os organismos comunitários do bairro possuíam suas ressalvas quanto à formula empregada pelo OCPM. Isso porque, segundo essas organizações, “(...) ela não permitiu uma larga participação pública, de modo que a transparência não esteve presente nos encontros, e que o exercício esteve menos ligado à uma visão de conjunto do que às intenções anunciadas pelos promotores" (OPA, relatório de resultados, 2009 - Tradução nossa). Os organismos da Action-Gardien, apesar disso, de forma estratégica, utilizaram os mecanismos de consulta pública, os "espaços convidados" da administração municipal. Em depoimentos coletados, fica clara a perspectiva estratégica do planejamento insurgente, a de resguardar a autonomia como forma de 
munir-se de argumentos mais precisos e validados socialmente e, sem desprezar as formas de participação institucionais, as "concessões" feitas pela administração pública. Estrategicamente, a combinação destas duas arenas de participação, uma mais autônoma e a outra mais sujeita ao conjunto de regras determinado pelo Estado, conduz a maiores chances de que as demandas elencadas nos espaços informais da esfera pública atinjam o centro do sistema político.

\section{Considerações finais}

O desenvolvimento nas imediações do canal de Lachine demonstra um processo em que a administração pública incentivou uma estratégia capitalista de urbanização, na qual as antigas usinas (de valor simbólico para a comunidade local) foram convertidas em condomínios de luxo para atrair uma clientela com pouco vínculo com a localidade, transformando a dinâmica do espaço por meio da revitalização urbana. 0 contexto neoliberal pode ser compreendido enquanto um processo político, no qual as negociações associadas ao planejamento urbano são levadas a autorizações que beneficiam tais projetos privados, em detrimento de espaços públicos que atendam às necessidades e aos desejos dos residentes, e em prejuízo de formas de decisão mais democráticas sobre a produção do espaço urbano. De forma participativa e com grande grau de independência em relação ao Estado, pelo intermédio das OPAs de Pointe-Saint-Charles, fortalecem-se laços de apropriação simbólica com o território e constróise uma visão coletiva sobre o terreno, a qual não se constitui em uma posição do tipo "not in my backyard", pois ultrapassa essa relação individual/individualista.

As práticas auto-organizadas de planejamento em Pointe-Saint-Charles podem ser ditas práticas de um planejamento insurgente, uma vez que contemplam elementos contra-hegemônicos, transgressivos e imaginativos. No universo de "espaços convidados" de um planejamento definido e conduzido conforme regras estipuladas pelo Estado, práticas como as OPAs são eventos pouco comuns, verdadeiras "exceções à regra", em termos de um planejamento urbano historicamente inserido dentro de uma lógica capitalista de produção da cidade. Há, nessas práticas, momentos e espaços de interação com o planejamento participativo institucional, mas também momentos e espaços de ruptura com esse planejamento oficial. Nesse sentido, a questão fundamental a ser considerada é que tais práticas são capazes de criar, por meio de mecanismos participativos autônomos, projetos e planos que, centralizando múltiplas visões locais em referência ao bairro, tornam-se um instrumento permanente de vigilância na disputa pelo território e de resistência em relação a projetos de empreendedores privados e planos de órgãos ligados à estrutura do Estado. Essas práticas revelam uma importante face do caráter conflitual da cidade contemporânea e apontam para um campo aberto de possibilidades quanto a uma necessária mudança em relação às práticas e teorias de planejamento urbano.

\section{Referências}

Action-Gardien. (2005). Opération populaire d'aménagement: les actes. Montréal: Action-Gardien.

Action-Gardien. (2009). Le site des ateliers du CN à Pointe-Saint-Charles: pour un développement qui répond aux besoins de la population et respecte l'identité du quartier. Montréal: Action-Gardien.

Blondiaux, L., \& Sintomer, Y. (2002). L'impératif délibératif. Politix, 15(57), 17-35.

http://dx.doi.org/10.3406/polix.2002.1205.

Cayer, J. (2013). Bâtiment 7: victoire populaire à Pointe-Saint-Charles. Les Éditions Écosociété.

Fischer, F., \& Forester, J. (1993). The argumentative turn in policy analysis and planning. Durham: Duke University Press. http://dx.doi.org/10.1215/9780822381815.

Forester, J. (1999). Deliberative practitioner: encouraging participatory planning process. Cambridge: The MIT Press. 
Friedmann, J. (2002). The prospect of cities. Minneapolis: University of Minnesota Press.

Gravel, F. (2012). La revitalisation de Pointe-Saint-Charles à Montréal: un cas de transformation des quartiers ouvriers péricentraux (Mestrado em Estudos Urbanos). Université du Québec, Montréal.

Grenier, G. (2008). L'opération populaire d'aménagement de Pointe-Saint-Charles: vers une appropriation du quartier par les citoyens sous l'initiative de la table de concertation Action-Gardien? (Mestrado em Geografia). Université du Québec, Montréal.

Habermas, J. (1985). The theory of communicative action: reason and the rationalization of society. Boston: Beacon Press.

Harvey, D. (2012). 0 direito à cidade. Lutas Sociais, (29), 73-89.

Harvey, D. (2013). A liberdade da cidade. In D. Harvey. Cidades rebeldes: passe livre e as manifestações que tomaram as ruas do Brasil. São Paulo: Boitempo editorial. pp. 27-34.

Healey, P. (1996). Planning through debate: the communicative turn in planning theory. In S. Campbell, \& S. Faistein (Eds.), Readings in planning theory. Cambridge: Blackwell. pp. 234-257.

Holston, J. (1995). Spaces of insurgent citizenship. Planning Theory, 13, 35-52,

Holston, J. (2008). Insurgent citizenship: disjunctions of democracy and modernity in Brazil. Princeton: Princeton University Press.

Innes, J. (1995). Planning theory's emerging paradigm: communicative action and interactive practice. Journal of Planning Education and Research, 14(3), 183-189. http://dx.doi.org/10.1177/0739456X9501400307.

Laclau, E. (1996). Emancipation(s). New York: Verso.

Laclau, E., \& Mouffe, C. (1985). Hegemony and socialist strategy: towards a radical democratic politics. London: Verso.

Latendresse, A., \& Manzi, M. (2018). Planejamento insurgente e direito à cidade: um olhar cruzado entre as experiências de planejamento de bairro de Montreal e Salvador. In A. Fernandes, \& M. Chagas (Org.), $O$ direito à cidade na França e no Brasil: uma nova agenda urbana? Questões para um debate necessário e fecundo: diálogos França-Brasil 4. Salvador: PPGAU/FAUBA/Lugar Comum.

Miraftab, F. (2009). Insurgent planning: situating radical planning in the global South. Planning Theory, 8(1), 3250. http://dx.doi.org/10.1177/1473095208099297.

Miraftab, F. (2016). Insurgência, planejamento e a perspectiva de um urbanismo humano. Revista Brasileira de Estudos Urbanos e Regionais, 18(3), 363-377. http://dx.doi.org/10.22296/2317-1529.2016v18n3p363.

Miraftab, F., \& Wills, S. (2005). Insurgency and space of active citizenship: the story of Western Cape anti-eviction campaign in South Africa. Journal of Planning Education and Research, 25(2), 200-217.

Mouffe, C. (2000). The democratic paradox. London: Verso.

Mouffe, C. (2002). Which public sphere for a democratic society. Theoria, 49(99), 55-65.

Mouffe, C. (2005). On the political. New York: Routledge.

Paré, J. (2008). Le rôle de l’office de consultation publique de Montréal. In M. Gauthier, M. Gariépy, \& M. Trépanier. Renouveler l'aménagement et l'urbanisme: planification territoriale, débat public et développement durable. Montréal: Les Presses de L'Université de Montréal.

Purcell, M. (2009). Resisting neoliberalization: communicative planning or counter-hegemonic movements? Planning Theory, 8(2), 140-165. http://dx.doi.org/10.1177/1473095209102232.

Rawls, J. (1971). A theory of justice. Cambridge: Harvard University Press.

Sandercock, L. (1999). Introduction translations: from insurgent planning practice to radical planning discourses. Plurimondi, 1(2), 37-46. 
Triollet, K. (2013). Une décennie de luttes urbaines à Pointe-Saint-Charles. Vers une réappropriation citoyenne. Nouveaux Cahiers du socialisme: Occupons la ville!, (10), 129-143.

Young, I. (1990). Justice and the politics of difference. Princeton: Princeton University Press.

Editor: Rodrigo José Firmino

Recebido: Fev. 22, 2018

Aprovado: Mai. 24, 2018 